\title{
ESTIMATION OF THE STRAIN TENSOR IN TUNNEL SECTIONS, BASED ON GEOMETRIC (GEODETIC ETC.) DATA
}

\author{
Kontogianni V.A., Roumanis M., Psimoulis, P.A., Sfeikos, A. and Stiros, S.C. \\ 1 Geodesy Lab. Department of Civil Engineering, University of Patras, 26 500, Patras, \\ vkont@civil.upatras.gr \\ ${ }^{2}$ Min. Of Public Works, Dept. for Acheloos Works, Trikala, aris3kala@yahoo.gr
}

\begin{abstract}
Monitoring of tunnel deformation during their excavation is based on measurements of displacements of either single points or contraction of selected distances across the tunnel section. Such data, however, due to measurement errors and local effects may not be consistent with each other, and cannot describe precisely the real behavior of the ground/support shell. In the present study, a theory introduced to estimate the ground surface strain field on the basis of surveying measurements is adopted in order to estimate the average strain of tunnel sections. This theory is based on the assumption of uniform deformation across the tunnel section and of measurements affected by random errors only and uses repeated monitoring data (displacements or distance changes).

The proposed theory was applied to deformation data from representative sections of the Acheloos Diversion Tunnel (Western Thessaly, Greece), subject to nearly uniform strain. Mean strain changes were estimated for various time intervals following the excavation. About one year after the excavation, maximum horizontal strain of $\sim 1.3 \%$, accompanied by practically negligible vertical strain, was computed.
\end{abstract}

\section{INTRODUCTION}

Deformation is a main factor controlling the failure and cost-effectiveness of underground excavations. For this reason deformation monitoring has become a fundamental requirement for assessing the stability of underground openings (Kaiser 1993). Deformation data are based on in situ geotechnical measurements (extensometers etc.) and tape measurements of selected distance changes, both providing information on local or relative dislocations only, or optical, geodetic records, which define absolute displacements of selected control points of tunnel sections (Kontogianni \& Stiros 2001).

A main characteristic of the observed tunnel deformation through soft rocks and soils, however, is that it does not correspond to uniform radial section closure (Fig.1a) that could be accurately measured by any of the above methods. On the contrary, strain in many tunnels is uniform across the deforming area, but the amplitude of radial displacement is variable along the tunnel periphery (non-radial deformation, Fig.1b; Schubert \& Schubert 1993; Kontogianni \& Stiros 2003); furthermore, in many cases non-uniform and non-radial deformation is observed (Fig.1c) and occasionally causes instabilities and failures (i.e. Tymfristos tunnel and Kallidromo tunnel, Greece, Kontogianni et al. 2004). However, in the case of non-radial deformation (either uniform or not, Figs.1b,c), the strain of tunnel sections cannot be directly calculated.

In addition, deformation data are usually affected by measurement errors and local instability effects, and hence, where redundant observations are available, observations are not compatible with each other (Fig. 2b) and the deformation tensor cannot be estimated. In the past, there have been efforts at solving this problem on the basis of graphical techniques (Moosavi and Khazaei 2003).

In the present paper, we present an analytical solution inspired from the studies of seismic/tectonic deformation in areas of strike slip faulting. This approach is justified from the fact that in strike slip faulting environments, deformation is nearly planar, as is also assumed to be the case 
with most tunnel sections; in general, a 2-dimensional model (i.e. on the basis of plane strain conditions) is assumed to simulate tunnel excavation (Hoek 2000; Leca et al. 2000).

The basic assumption of the proposed method is that deformation is uniform, i.e. that strain (i.e. the ratio of the distance change to the distance between two control points) is simply a function of the orientation of the line defined by two control points.

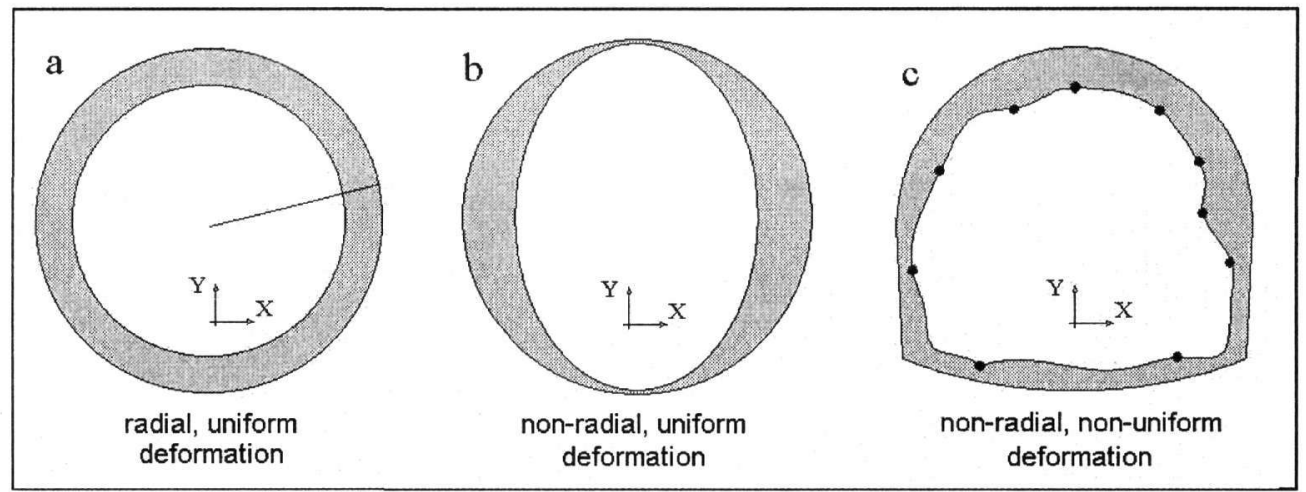

Figure 1. A sketch to show different types of strain field across tunnels (simplified from Kontogianni et al. 2004).

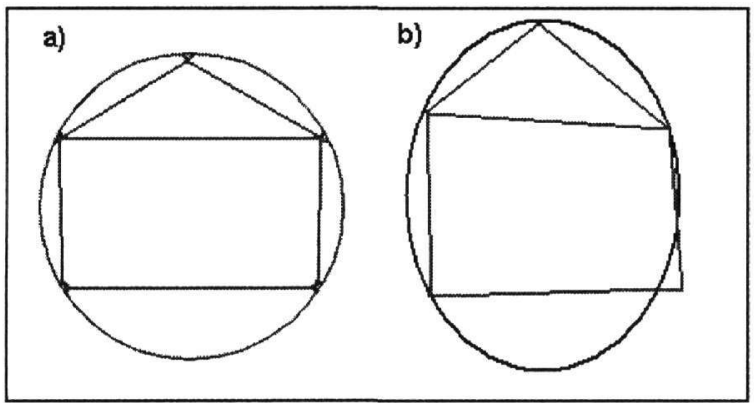

Figure 2. a) Observed line length changes across a tunnel section, using a tape, b) sketch of the deformed section (exaggerated): observations are not compatible with each other, and extended lines do not fit to an ellipse, mainly due to measurements errors.

\section{ESTIMATION OF AVERAGE STRAIN IN TECTONICALLY ACTIVE AREAS}

Frank (1966) based on the fact that strike-slip and transform faults produce two-dimensional uniform strain on the ground surface, was the first to compute the average strain field across such seismic regions. His study was based on repeated measurements of triangulation networks crossing fault zones and he estimated the average principal strains of his study areas. A basic requirement for this analysis is that measurements include random errors only. This analysis was later generalized and applied to several studies of surface deformation of the San Andreas, California, fault zone (Prescott et al. 1979; Savage 1983; Fig.3) and other regions.

In this analysis, it is assumed that a certain network of $\mathrm{n}$ lines covers a study area, for instance that of figure 3. Between two surveys the length of line $i$ of initial length $L_{i}$ was increased by an amount $\Delta \mathrm{L}_{\mathrm{i}}$. Strain along this line is defined by the equation $\varepsilon_{\mathrm{i}}=\Delta \mathrm{L}_{\mathrm{i}} / \mathrm{L}_{\mathrm{i}}$. Assuming a uniform strain, the observed strain $\varepsilon_{i}$ along this line is related to $E_{11}, E_{22}$ and $E_{12}$, i.e. the tensor components of strain along the $x$ and $y$ axes and the shear component of strain in a direction of the $x$ axis (Fig.4), by the equation:

$\varepsilon_{i}=\mathrm{E}_{11} \bullet \sin ^{2} \theta_{\mathrm{i}}+\mathrm{E}_{12} \bullet \sin 2 \theta_{\mathrm{i}}+\mathrm{E}_{22} \bullet \cos ^{2} \theta_{\mathrm{i}}$ eq 1

where $\theta_{i}$ is the approximate azimuth of the line (measured clockwise from north). 


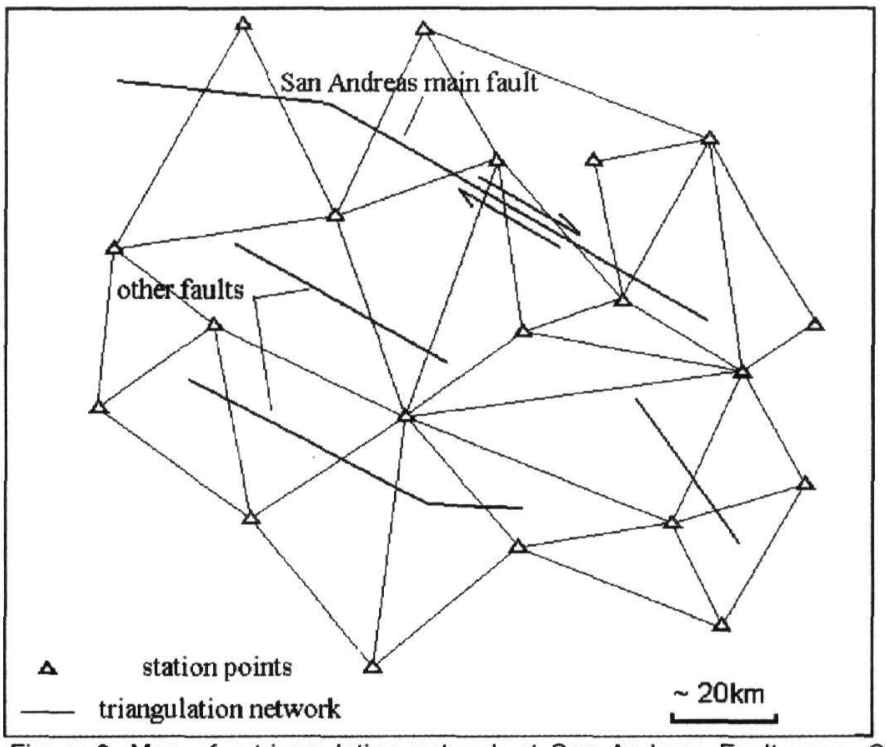

Figure 3. Map of a triangulation network at San Andreas Fault zone, California established for studying the strain tensor. Major faults are shown in black lines. Despite faulting, strain is assumed uniform, i.e. depending on the azimuth of the observation line only. After Savage (1983) simplified.

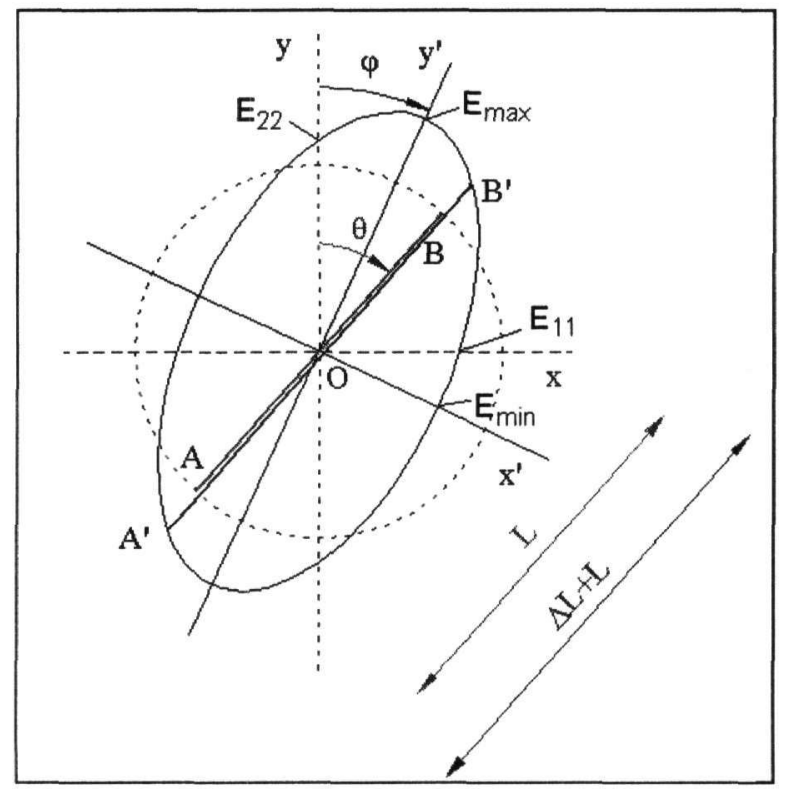

Figure 4. Geometric representation of our model, a circle (corresponding to a part of the earth's surface) deformed to an ellipse. All parameters for calculating the strain field based on the Frank's (1966) theory are shown.

Each observation of line length change contributes with one equation of this type, and finally a system of $n$ linear equations is formed. In this system $E_{11}, E_{22}$ and $E_{12}$ are unknowns. Solving this system using standard least square techniques, $E_{11}, E_{22}$ and $E_{12}$ as well as their uncertainties, can be estimated. At a second step, the principal (maximum and minimum) strains and their directions are calculated based on the equations: 
$\varepsilon_{\max }=\frac{E_{11}+E_{22}}{2}+\sqrt{\frac{E_{11}-E_{22}^{2}}{2}+E_{12}^{2}}$

$\varepsilon_{\min }=\frac{E_{11}+E_{22}}{2}-\sqrt{\frac{E_{11}-E_{22}^{2}}{2}+E_{12}^{2}}$

$\tan \varphi=\frac{2 \cdot E_{12}}{E_{22}-E_{11}}$

eq 4

where $\varphi$ is the azimuth of direction of maximum principal strain $\left(\varepsilon_{\max }\right)$.

\section{ESTIMATION OF THE AVERAGE STRAIN IN A TUNNEL}

The approach of Frank (1966) permits to estimate the average deformation (average strain tensor) of a horizontal area in the earth's surface assuming that this deformation is associated with insignificant vertical deformation (plane strain conditions). There are lines of evidence indicating that in most cases deformation of tunnel sections can also be described by plane strain conditions, i.e. that deformation is limited to a vertical plane, and deformation along the tunnel axis is a secondorder effect (Hoek 2000; Leca et al. 2000).

Furthermore, it can be assumed that the deformation of the tunnels sections is uniform (i.e. parallel lines in the same section have the same strain) and monitoring data of at least a number of tunnels are not contaminated by systematic errors and blunders. Hence, the approach described above for horizontal surfaces can be adopted for the vertical surfaces of tunnel sections and their average strain can be computed, using the equations described above.

Schematically, this approach can be described as the computation of the parameters of an ellipse resulting from the deformation of a circle (i.e. of a tunnel section) of unit diameter (Fig. 5).

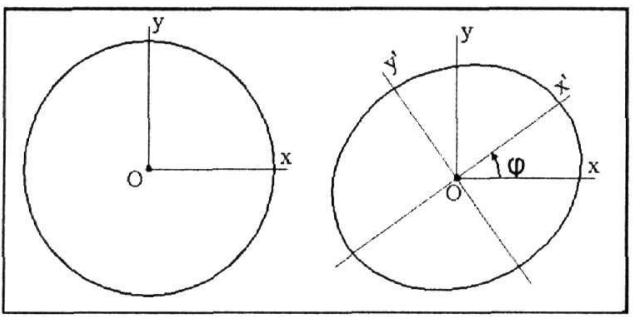

Figure 5. Due to strain, a circle of unit radius is transformed to an ellipse. Equations and techniques described above permit to calculate the length and orientation of the main axes of this ellipse.

\section{A CASE STUDY}

The approach described above was applied to the analysis of the deformation of a segment of the Acheloos Diversion Tunnel, western Thessaly, Greece. This tunnel was selected as a case study because it satisfies the requirements of the method explicitly analyzed above. In particular, the deformation of the tunnel sections is assumed uniform along long distances, the quality of measurements is high, and redundant measurements for a number of sections (see below) were available. This monitoring record covered a period of $>400$ days.

\subsection{The Acheloos Diversion Tunnel, western Thessaly, Greece}

The Acheloos River Diversion Tunnel, is designed to be $17.4 \mathrm{~km}$ long with an internal diameter after lining of least $6 \mathrm{~m}$. Excavation is still active (May 2004) with a full face open shield TBM (construction from WIRTH) with an excavation diameter of $7.1 \mathrm{~m}$. Tunneling commences from water outlet station towards inlet with an upwards inclination of $0.3 \%$ mean value. During the first $3.5 \mathrm{~km}$ upstream, tunneling advanced through high strength limestones, interchanges of cherts, marly cherts and cherty siltstones and members of the Pindos Flysch (silt-clay and sand-stones, Sfeikos \& Marinos 2004).

However, along a distance of $30 \mathrm{~m}$, when the tunnel entered to a zone of flysch (siltstones 
and sandstones) probably corresponding to a thrust zone (ch. $16+250 \mathrm{~m}$ to $16+280 \mathrm{~m}$, at $\sim 400 \mathrm{~m}$ overburden), observed displacements were about one order higher than in the adjacent limestone sections, despite the relatively stiff support (steel ribs HEB $140 / 75 \mathrm{~cm}$, wire mess T140,12cm shotcrete shell). Deformation continued for more than 12 months after excavation and led to cracking and detachment of shotcrete, additional contraction of $\sim 6 \mathrm{~cm}$, floor heave and lateral displacement of preconstruction invert. The support measure lining was subsequently repaired (new steel ribs HEB140 and repairs to the shotcrete shell) and deformation was finally stabilized. No significant deformation to the adjacent sections was, however, observed.

Deformation monitoring of Acheloos Diversion Tunnel was based on measurements of distances across tunnel section with a tape extensometer of high accuracy $(0.13 \mathrm{~mm} / 10 \mathrm{~m}$, Dunnicliff, 1993). Five pins were fixed at each control section and 6 different distances were measured (Fig.6). The complete set of measured distances for 8 different control sections covering a distance of more than $1.5 \mathrm{~km}$ along the tunnel axis and $\sim 400$ days were available for our study. In the following paragraph we analyze the estimation of the strain field in one of these sections (ch. $16+276 \mathrm{~m}$ ), located in the weak zone of increased deformation.

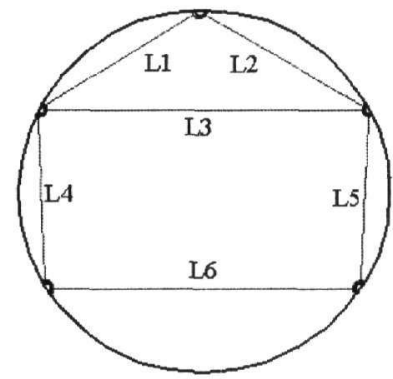

Figure 6. Drawing of a typical control section of Acheloos Diversion Tunnel. The 6 distances repeatedly measured with a convergence tape are marked $\mathrm{L} 1$ to $\mathrm{L} 6$.

\subsection{Computation of the final strain tensor}

The cumulative (final) deformation of the 6 control lines (for instance 0.0033 for line L1, corresponding to a total length change of $6.8 \mathrm{~mm}$ along a distance of $2.086 \mathrm{~m}$ ), surveyed for a period of $\sim 400$ days after section excavation, and the azimuth of each line (for instance $253^{\circ}$ for line L1, $116^{\circ}$ for line L2 etc.) were the input parameters to the equation for the strain tensor estimation (eq.1). One equation was written for each line; thus, the following system of 6 linear equations with 3 unknown parameters (strains $E_{11}, E_{12}$ and $E_{22}$ ) was formulated as below:

$$
\begin{aligned}
& 0.0033=E_{11} \cdot \sin ^{2}\left(253^{\circ}\right)+E_{12} \cdot \sin \left(2 \cdot 253^{\circ}\right)+E_{22} \cdot \cos ^{2}\left(253^{\circ}\right) \\
& 0.0136=E_{11} \cdot \sin ^{2}\left(116^{\circ}\right)+E_{12} \cdot \sin \left(2 \cdot 116^{\circ}\right)+E_{22} \cdot \cos ^{2}\left(116^{\circ}\right) \\
& 0.0172=E_{11} \cdot \sin ^{2}\left(99^{\circ}\right)+E_{12} \cdot \sin \left(2 \cdot 99^{\circ}\right)+E_{22} \cdot \cos ^{2}\left(99^{\circ}\right) \\
& 0.0007=E_{11} \cdot \sin ^{2}\left(201^{\circ}\right)+E_{12} \cdot \sin \left(2 \cdot 201^{\circ}\right)+E_{22} \cdot \cos ^{2}\left(201^{\circ}\right) \\
& 0.0000=E_{11} \cdot \sin ^{2}\left(172^{\circ}\right)+E_{12} \cdot \sin \left(2 \cdot 172^{\circ}\right)+E_{22} \cdot \cos ^{2}\left(172^{\circ}\right) \\
& 0.0150=E_{11} \cdot \sin ^{2}\left(94^{\circ}\right)+E_{12} \cdot \sin \left(2 \cdot 94^{\circ}\right)+E_{22} \cdot \cos ^{2}\left(94^{\circ}\right)
\end{aligned}
$$

Solving the above system on the basis of the least squares method and the Mathematica software, the following strain tensor parameters and their uncertainties were obtained:

$E_{11}=0.0105 \pm 0.0023$
$E_{12}=-0.0054 \pm 0.0034$
$E_{22}=-4.07^{\star 1} 10^{-5} \pm 0.0032$

It is obvious that $E_{22}$ (strain value at the vertical direction) is statistically not significant, in contrast to the $E_{11}$ and $E_{12}$ strain tensor components. The principal strain values were subsequently calculated from eqs. 2, 3 and $4: \varepsilon_{\max }=0.013, \varepsilon_{\min }=0$ and $\varphi=0.4^{\circ}$. Finally, the deformed section was designed using AUTOCAD software (Fig.7). 


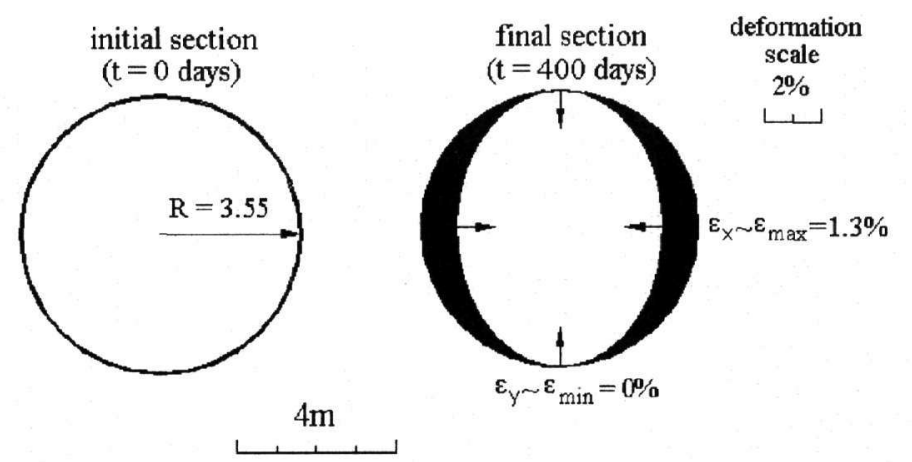

Figure 7. Schematic comparison of the initial and of the final (exaggerated) form of a representative section of Acheloos Diversion Tunnel (ch. 16+276m), 400 days after the excavation.

Similar calculations were made using deformation data collected at various times since the section excavation. This analysis revealed that the strain field of the study sections was gradually changing with time, as is schematically shown in figure 8 , and that deformation was accumulating until the initially circular section was transformed to an ellipse.
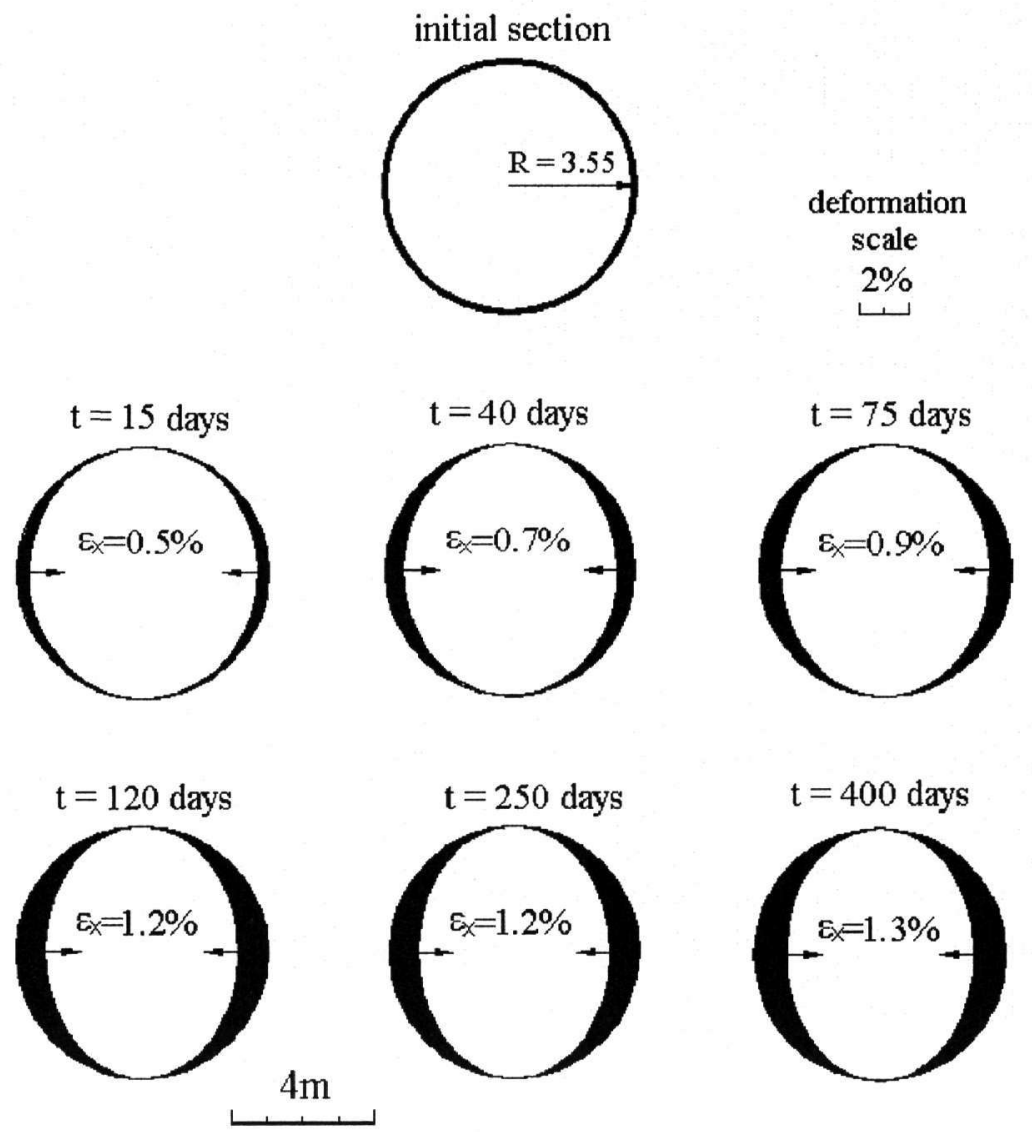

Figure 8. Progressive change of the section strain field along time. Horizontal strain $\left(\varepsilon_{x}\right)$ accumulates gradually to $1.3 \%$ (corresponding to maximum strain), whereas vertical strain remains 0 . 


\section{CONCLUSIONS}

The Frank's (1966) methodology for calculating ground surface strains across several seismic regions on the basis of repeated geodetic measurements is adopted for the estimation of the average strain of tunnel sections during excavation. The analysis uses the deformation monitoring data, either geodetic or geotechnical (extensometers etc.), and estimates the strain tensor parameters by least squares calculations. The only requirements are first, uniform deformation across the section and second, measurements influenced by random errors only. Both these requirements are fulfilled by several tunnels cut through homogeneous ground conditions and following careful monitoring programs.

The application of this methodology on the Acheloos Diversion Tunnel data showed that the deformed section corresponds to an ellipse, with major axis at the vertical direction; the horizontal contraction reaches $1.3 \%$ after $\sim 400$ days after excavation but no vertical deformation is calculated. Furthermore, the calculation of the strain field parameters for several time periods after excavation reveals the kinematic response of the tunnel section to the excavation along time.

\section{ACKNOWLEDGEMENTS}

This is a contribution to the PENED and EPAN-PRAXE Projects of the Greek Secretariat of Research and Technology.

\section{REFERENCES}

Dunnicliff J. 1993. Geotechnical Instrumentation for Monitoring Field Performance. New York, John Wiley \& Sons, Inc., 577pp.

Frank F.C. 1966. Deduction of earth strains from survey data, Bull. Seismol. Soc. Amer., 56, 35-42.

Hoek E. 2000. Practical Rock Engineering, Rotterdam, Balkema.

Kaiser P. 1993. Deformation Monitoring for Stability Assessment of Underground Openings. Compressive Rock Engineering, Bergamon, 4, 607-630.

Kontogianni V.A. \& Stiros S.C. 2001. Geodetic monitoring of tunnel deformation, Bull. of the Geological Society of Greece, 34 (5), 1671-1677 (in Greek, with English abstract).

Kontogianni V. \& Stiros S. 2003. Tunnel Monitoring during the Excavation Phase: 3-D Kinematic Analysis based on Geodetic Data, Proc. of the $11^{\text {th }}$ FIG Symposium on Deformation Measurements, Santorini Island, Greece, 397-402. Also at the Internet address http://umw.fig.net/commission6/santorini/F-Tunnels/F3.pdf

Kontogianni V.A. Tzortzis A. \& Stiros S.C. 2004. Deformation and Failure of the Tymfristos Tunnel, Greece, Journal of Geotechnical and Geoenvironmental Engineering, ASCE (in press).

Leca E. Leblais Y. \& Kuhnhenn K. 2000. Underground works in soils and soft rock tunnelling, Proc. Int. Conf. on Geotech. and Geolog. Eng., 1, 220-268.

Moosavi M. \& Khazaei S. 2003. Absolute deformation profile determination in tunnels using relative convergence measurements, Proc. of the $11^{\text {th }}$ FIG Symposium on Deformation Measurements, Santorini Island, Greece, 403-408. Also at the Internet address http://www.fig.net/commission6/santorini/F-Tunnels/F4.pdf

Prescott W.H. Savage J.C. \& Kinoshita W.T. 1979. Strain accumulation rates in the western United States between 1970 and 1978, Journal of Geophysical Research, 84 (B10), 5423-5435.

Savage J.C. 1983. Strain accumulation in western United States, Ann. Rev. on Earth Planet. Sci., 11, 11-43.

Schubert W. \& Schubert P. 1993. Tunnels in squeezing rock: Failure phenomena and counteractions, Proc. of the Assessment and Prevention of Failure Phenomena in Rock Engineering, Rotterdam, Balkema, 479-484.

Sfeikos A. \& Marinos P. 2004. Behavior of Pindos Flysch during tunnelling through a thrust zone. Deformation and rock behavior. Expierence from the Acheloos River Diversion Tunnel to Thessaly. Bulletin of the Geological Society of Greece, this volume. 